\title{
"O livro como uma força na História": a bibliografia como fonte de informação e método de pesquisa
}

"The book as a force in History": bibliography as information source and research method

Wesley Augusto Nogueira

Doutorando em Ciência da Informação pelo Programa de Pós-graduação em Ciência da Informação pela Escola de Comunicações e Artes da Universidade de São Paulo - ECA/USP. e-mail: wesley.nogueira@uol.com.br

\section{Resumo}

A História do Livro e a Ciência da Informação compartilham a característica de serem campos do conhecimento cuja epistemologia é composta pela interdisciplinaridade. A partir desta constatação, propõe-se a contribuição de mais um campo na miríade de disciplinas que as formam: a bibliografia, como fonte de informação e como método de pesquisa para ambas as áreas.

Palavras chave: Bibliografia. História do Livro. Ciência da Informação. Produção editorial. Colecionismo.

\begin{abstract}
The Book History and the Information Science share the characteristic of being fields of knowledge whose epistemology is composed of interdisciplinarity. From this fact, it is proposed the contribution of another field in the myriad of disciplines that form them: the bibliography, as a source of information and as a research method to booth areas.
\end{abstract}

Keywords: Bibliography. Book History. Information Science. Editorial production. Book collecting. 


\section{Introdução}

A bibliografia, desde sua origem, nas coleções de livros reunidas e descritas pelos primeiros impressores e bibliófilos, pautou-se pelo seu caráter instrumental, como método de organização da informação através de catálogos bibliográficos e documentais. Propõe-se, neste estudo, realizar algumas reflexões sobre sua contribuição também como metodologia de pesquisa para os estudos em História do Livro e Ciência da Informação.

Robert Darnton (2010, p. 122-123) demonstra que a História do Livro nasceu da reunião de pesquisadores de diferentes áreas que viam seus interesses confluírem para a percepção do "[...] livro como uma força na História". Do mesmo modo, a Ciência da Informação originouse da conjunção de diversas áreas do conhecimento, como Psicologia (Psicologia da Informação), Sociologia (Sociologia da Informação), Economia (Economia da Informação), Ciência Política (Política da Informação) e Tecnologia (Tecnologia da Informação), que contemplam os "processos de informação ou seus componentes" (WERSIG; NEVELLING, 1975, p 36). Tanto a História do Livro quanto a Ciência da Informação, portanto, sob o ponto de vista da gênese epistemológica interdisciplinar, são compostas pela convergência de diferentes áreas do conhecimento com um objeto comum: a informação, na Ciência da Informação, e o livro, na história do livro.

Para a História do Livro, assim como para qualquer ciência ou campo de estudo, a organização dos documentos é indispensável para que o trabalho do pesquisador alcance um maior grau de eficiência.

A bibliografia, enquanto produto gerado pela ordenação de documentos, exerce a função de disponibilizar dados e também o roteiro para acesso aos originais, permitindo que se faça análises (dependendo do caso, de longo período) sobre autores, editores, livreiros, tipógrafos, impressores e outros agentes da cadeia produtiva do livro, tão caros aos estudos na área.

Já enquanto disciplina, proporciona um método eficaz de investigação de livros e documentos sob a forma de textos impressos, pelo qual merece ter sua relevância para o campo ressaltada, considerando-se a significativa contribuição que a tradição bibliográfica de análise do texto inscrito em diferentes suportes proporciona ao historiador.

A História do Livro, como campo do conhecimento, começa se estruturar a partir da década de 1960 e, enquanto crescia e ganhava destaque como nova área de estudos, a 
"O livro como uma força na História": a bibliografia como fonte de informação e método de pesquisa

bibliografia, por sua vez, silenciava-se em um ostracismo que só recentemente foi superado, a partir, principalmente, das proposições do bibliógrafo Donald McKenzie. Para McKenzie (1999, p.12-13, tradução nossa), a "bibliografia é a disciplina que estuda os textos como formas gravadas, e os processos de sua transmissão, incluindo sua produção e recepção". Sob este aspecto, a “[...] forma afeta o significado", motivo pelo qual não se deve pesquisar apenas os processos técnicos de transmissão bibliográfica, mas também os sociais.

Os estudos de McKenzie contribuíram, dessa maneira, para a restituição das circunstâncias em que os textos influem e são influenciados pelas sociedades ao longo do tempo e modificaram a visão que popularmente se tinha da bibliografia, ao propor que a materialidade do texto (seu suporte) exercia um importante papel em seu significado e que todo texto era produto de uma complexa rede de fatores externos, envolvendo agentes e questões de autoria, produção e circulação, a que chamou de "sociologia dos textos". Indo além, aproxima as três áreas ao definir que o estudo das formas impressas pode ser chamado de história do livro, sociologia dos textos ou, já que o livro tradicionalmente sempre foi sua fonte e substância, bibliografia.

Aberta a diferentes perspectivas, a História do Livro não apresenta com frequência olhares investigativos acerca do próprio campo. O que se pretende propor aqui é o estabelecimento da função da bibliografia para a História do Livro, através de uma abordagem metodológica e informacional, e por consequência, também para a Ciência da Informação, a partir da ótica da produção, circulação e apropriação da informação. Serão apresentados exemplos de como a análise bibliográfica pode revelar pistas importantes para a compreensão dos mecanismos de produção e recepção do livro nacional contemporâneo, com enfoque nas coleções editoriais vendidas em banca de jornais durante os anos 1970, objeto de investigação proposto em minha pesquisa de doutorado. 


\section{Os tipos de bibliografia}

A bibliografia pode ser compreendida como fonte de informação, enquanto produto, ou como método, sob o aspecto disciplinar. Basicamente, a bibliografia popularmente conhecida, sob a forma de uma lista de documentos organizados, é, na verdade, um produto bibliográfico, o resultado de um processo pelo qual se gera um catálogo de livros ou documentos.

E é a esse tipo de catálogo, denominado bibliografia enumerativa (Fig. 1), que em um primeiro momento os pesquisadores recorrem para perfilar obras e dados relevantes à sua investigação ou ao preparo de um projeto de pesquisa. A bibliografia enumerativa é o tipo mais elementar de bibliografia, pois consiste na simples enumeração de títulos referentes a um documento ou um acervo. Em alguns casos, é o único recurso de que algumas unidades de informação dispõe e demandam grande trabalho do usuário para a análise de quais títulos são ou não pertinentes.

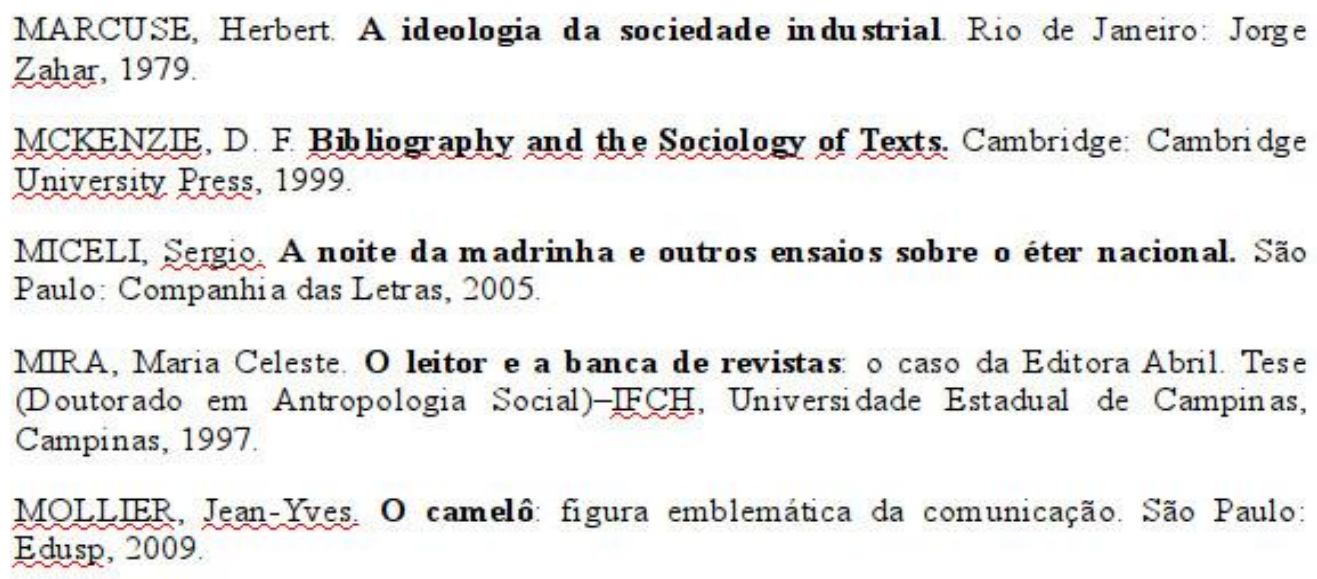

Em unidades onde os catálogos estão melhores desenvolvidos, estão disponíveis as bibliografias sistemáticas, que são bibliografias enumerativas sistematizadas, ou seja, organizadas por tema, autor, data, local de publicação, entre outros. Permitem a economia de tempo para o conhecimento dos livros disponíveis e são produtos indispensáveis a acervos de maior porte, oferecidos de forma física ou digital, sendo mais comum, atualmente, a segunda. Há possibilidade, ainda, de serem enriquecidas com comentários, ilustrações e referências que a tornam ainda mais completa e específica. 
"O livro como uma força na História": a bibliografia como fonte de informação e método de pesquisa

Um segundo e mais desenvolvido produto bibliográfico são as bibliografias analíticas (Fig. 2) também definidas como bibliografias materiais. Inicialmente, a bibliografia analítica tinha por função auxiliar no estabelecimento de textos originais ou versões definitivas, e foi muito utilizada para reestabelecer textos de Shakespeare, por exemplo. A crítica textual foi a primeira atividade da bibliografia analítica e aproveitava-se de todos os detalhes presentes no livro impresso, como falhas na impressão, defeitos nos tipos, marcas (réglures, pontusais, filigranas) e características do papel, para identificar o processo de produção ou ao menos chegar próximo do que teria sido o texto original, recriando as etapas e investigando os responsáveis pela sua elaboração, entre os quais os autores, editores, impressores, vendedores e comerciantes.

L'ARRIVEE// DES PERES CAPVCINS,//\& la conuersion des Sauuages à// nostre saincte foy. Declaree par// le R. P. CLAVDE D'ABBEVILLE// Predicateur Capuçin.// [vinheta]// A PARIS,// chez IEAN NIGAVT ruê S. lean// de Latran à l'Alde.// M.D.C.XIII.// Auec Permission.//

16 p. -- Assinatura: A-B(4)

Verso da página de rosto: em branco.

P. 3-10: [barra ornamental]//L'ARRIVEE DES PERES// Capucins, \& la cõuersion des Sauua-//ges à nostre saincte foy. Declaree// par le R. P. Claude d'Abbe-// uille Predicateur Capuçin.//

P. 10, termina [assinado no final:] "Mon bien-aymé Frere.// En haste, De Maraguon,// [sic] au Brezil// ce 20. iour d'Aoust, 1612.// Vostre petit Frere, \& seruiteur en// Nostre Seigneur.// Frere Claude d'Abbeuille, Capuçin indi-// gne \& Indien pour le present."//

P. 11-15: - // SOMMAIRE RELATION DE// quelques autres choses plus particulieres qui// ont esté dictes de bouche aux Peres Capu//cins par Monsieur de Manoir//

P. 15-16: - // LETTRE QVE LES PERES CA-// pucins ont escrit à Monsieur Fermanet// [assinado no final:] Vos tres-humbles seruiteurs en nostre// Seigneur Frere Claude d'Abbeuille,// Frere Arsene de Paris.// De l'Isle de Maraguonce [sic] 20. Aoust, 1612.// FIN.//

Trata-se de obra raríssima.

Dr. Rubens Borba de Moraes cita uma edição anterior de 1612.

Segundo Leclerc, essas cartas são recomendadas por sua novidade e por precederem de um ano a publicação da história da missão dos padres Capuchinhos. Dão estas cartas as primeiras noticias da nova missão, cujos historiadores mais conhecidos foram o próprio Claude d'Abbeville e o padre Yves d'Evreux.

É edição não mencionada por Brunet e Ternaux-Compans.

Existem traduções para o italiano "In Bergamo, per Comim Ventura \& ristampata in Treviso, per Angelo Reghettini 1613", além da alemã do mesmo ano "gedruckt zu Augspurg durch Chrysostomum Dabertzhofer".

Em 1876 foi feita uma reimpressão em Lyon por Louis Perrin, com poucos exemplares e datados na folha de rosto de 1623 .

Figura 2 - Exemplo de bibliografia analítica

Fonte: UNIVERSIDADE DE SÃO PAULO, 2002.

As bibliografias bem elaboradas podem revelar aspectos importantes para a composição do corpus informacional que será utilizado pelo historiador do livro em sua narrativa. Detalhes como o tipo de material usado por um impressor, as variações em clichês de uma mesma edição, autógrafos ou notas de posse são fontes importantes para a compreensão dos métodos de produção e circulação do livro em determinada região e época. Mesmo as ausências têm 
potencial para dizer, por exemplo, sobre a censura (oficial ou social), a distribuição e o público de uma obra ou de um autor.

Não há um consenso sobre quais áreas compõem a bibliografia analítica, mas três são frequentemente citadas: a bibliografia descritiva, a textual e a histórica. Enquanto a bibliografia descritiva procura catalogar todas as informações materiais de um exemplar, a bibliografia textual, também conhecida crítica, tenta estabelecer as variações em um texto impresso e a responsabilidade que cada ator da cadeia produtiva tem sobre elas. Já a bibliografia histórica seria a que mais se aproxima da História do Livro, pois tem por objetivo específico investigar as relações entre os livros e a sociedade que os produziu. Para McKenzie, a disseminação das obras e sua leitura estavam profundamente imbricadas a questões políticas e econômicas, que, conforme julga, são de fundamental interesse à História do Livro.

\section{A bibliografia material}

A bibliografia analítica ou material foi muito utilizada a partir da necessidade comercial de vendedores de livros raros em descrever fielmente as obras que disponibilizavam, muitas vezes volumes com poucos exemplares conhecidos, em que cada detalhe poderia significar o acréscimo ou a perda do valor do objeto. Esse ramo da bibliografia esteve intimamente relacionado à questão do colecionismo e da bibliofilia.

Conforme demonstrado, a bibliografia, enquanto disciplina, reestruturou a maneira de se estudar o livro e os textos ao ser utilizada para a investigação dos modos como o suporte altera o sentido da leitura. Sua aplicação como instrumento de análise reformulou as pesquisas em crítica literária, que passaram a considerar os textos a partir das formas que o conservaram, procurando compreender seu caminho em um ciclo informacional que envolve a produção, circulação e recepção.

Desta maneira, aliada aos fatores semânticos, a bibliografia material contribui de maneira significativa com o campo de estudos do livro, que têm procurado, nas palavras de Chartier (2002, p. 251-252), “[...]reinscrever as obras na história”, pois, se "por um lado, é em função das competências e das expectativas supostas do público visado que são organizadas as formas dadas aos textos, [...] por outro lado os dispositivos através dos quais um texto é proposto (para leitura ou para escuta) têm uma dinâmica própria: conforme o que são, podem ou não criar um público novo e autorizar apropriações inéditas”.

InCID: R. Ci. Inf. e Doc., Ribeirão Preto, v. 7, n. esp., p. 152-164, ago. 2016. 
"O livro como uma força na História": a bibliografia como fonte de informação e método de pesquisa

Sob este aspecto, a bibliografia demonstra-se uma ferramenta útil para a análise dos movimento de cultura de massa e das indústrias culturais, criadoras por excelência de novos públicos para obtenção de escala que viabilize economicamente seus produtos. As coleções de livros lançadas pela editora Abril Cultural na década de 1970 são um exemplo típico da formação de público para a recepção de obras muitas vezes estranhas ao seu gosto e as estratégias da editora revelam-se em suas obras, através de sua forma e conteúdo.

Os livros das coleções Abril, majoritariamente reedições, foram destinados a um público diferente e recebidos de forma distinta daquela que os leitores originais os recepcionaram, em diferentes condições sociais, históricas e geopolíticas. A coleção bibliográfica padroniza materialmente a forma para tentar o mesmo efeito no sentido: transmitir ao leitor a sensação de que, amparado pelo fascículo, pelo ponto de distribuição, pela facilidade de acesso físico e econômico e pela escolha prévia dos títulos, possa também acessar intelectualmente seus textos. Sob este aspecto, Montaigne e Sartre, Dostoievski e Huxley, juntos em uma mesma coleção, foram, em sua forma, obras homogêneas para os leitores das coleções Abril.

\section{A aplicação da bibliografia à análise material de edições contemporâneas}

A adoção da bibliografia material como método de pesquisa oferece, dessa maneira, informações relevantes sobre o formato do livro, tipo e qualidade da capa e do papel do miolo, tamanho da fonte e mancha, forma de encadernação, entre outros itens analisáveis que podem ser úteis para a compreensão do sistema de produção e circulação e o público para o qual se destina a obra.

O desafio que se apresentou durante os primeiros estágios da pesquisa com os livros da Abril Cultural foi o reestabelecimento do catálogo editorial ao menos das principais publicações da editora. O contato com o Departamento de Documentação da empresa não foi produtivo, uma vez que a unidade não possuem registrados os livros lançados durante os anos 1970, embora tenha sido criada em 1968. Da mesma maneira, não foi feito o depósito no Departamento das obras lançadas durante esse período, sendo que os volumes hoje disponíveis no arquivo são frutos de doações posteriores, o que reflete as muitas lacunas do acervo.

A partir da dificuldade em reconstituir o catálogo de livros publicados, foi necessário lançar mão de artifícios como a consulta a redes sociais de leitores, onde a contribuição coletiva permite o levantamento de exemplares particulares, e a busca em um canal pouco valorizado 
nas pesquisas sobre História do Livro: os sebos, ou alfarrábios, como preferem alguns. Estes estabelecimentos comerciais, voltados à venda de livros de segunda mão, tradicionalmente são frequentados por colecionadores, bibliófilos e estudiosos, e embora não sejam propriamente dispositivos de informação, fornecem dados valiosos ao pesquisador que se propõe a perscrutar seus corredores por vezes estreitos e poeirentos, com estantes repletas de livros em sua maioria reféns de desorganização e falta de conservação.

Percorrendo uma série de lojas de livros usados, em várias cidades do Brasil e em Buenos Aires, na Argentina, foi possível encontrar obras publicadas pela Editorial Abril, predecessora portenha fundada por César Civita, irmão de Victor, presidente organizador da Abril nacional, além de volumes ainda embalados e plastificados (Figs. 3 e 4), o que depois de mais de quatro décadas de publicação, parecem indicar que seus antigos proprietários realizaram uma compra impulsiva ou conspícua da obra. No estágio atual da pesquisa, uma generalização sobre este aspecto não seria adequada, mas também não se deve desconsiderar este indício em análises mais aprofundadas num segundo momento.

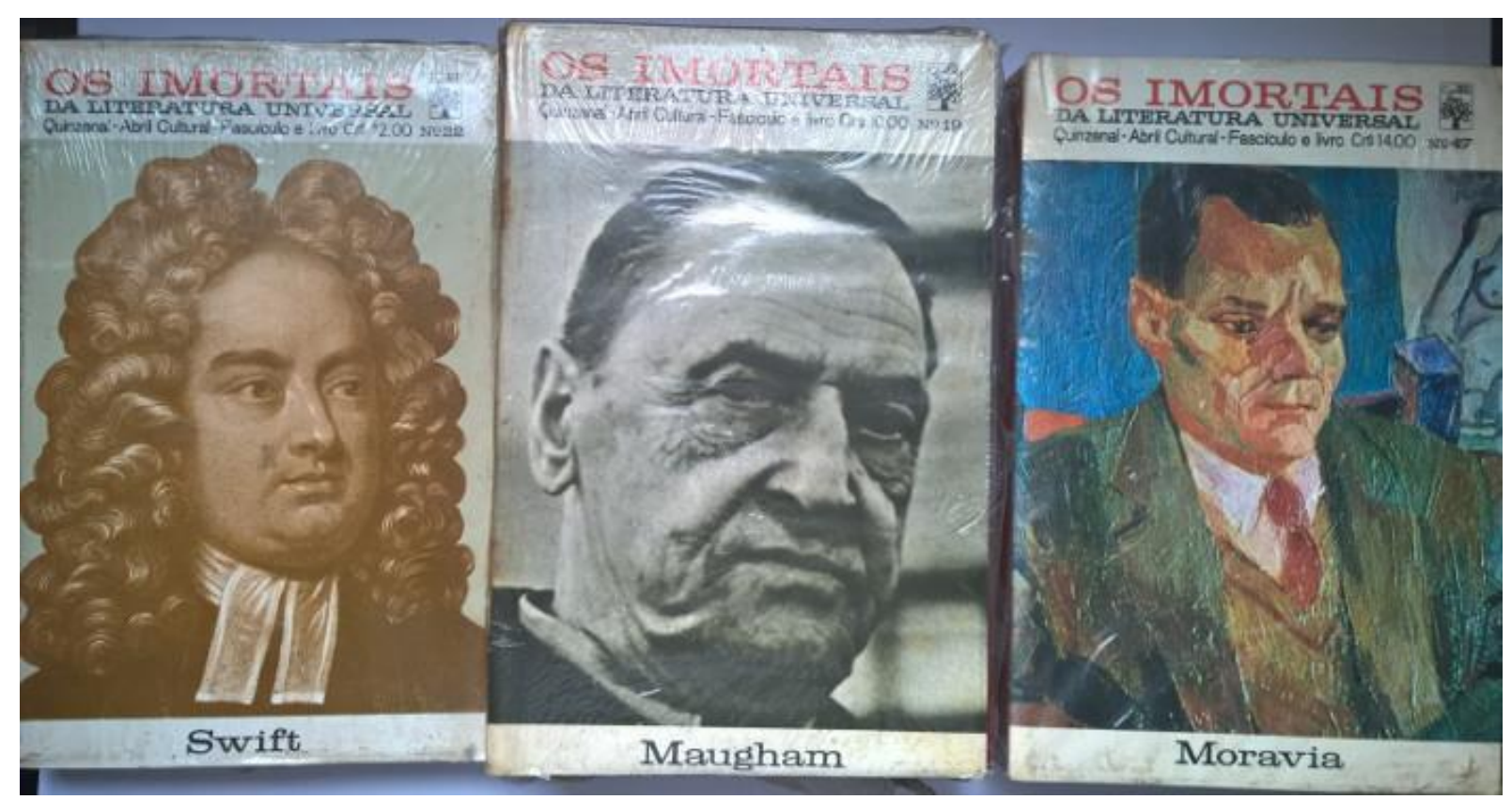

Figura 3 - Edições ainda plastificadas, contendo o fascículo original Fonte: Acervo pessoal. 
"O livro como uma força na História": a bibliografia como fonte de informação e método de pesquisa

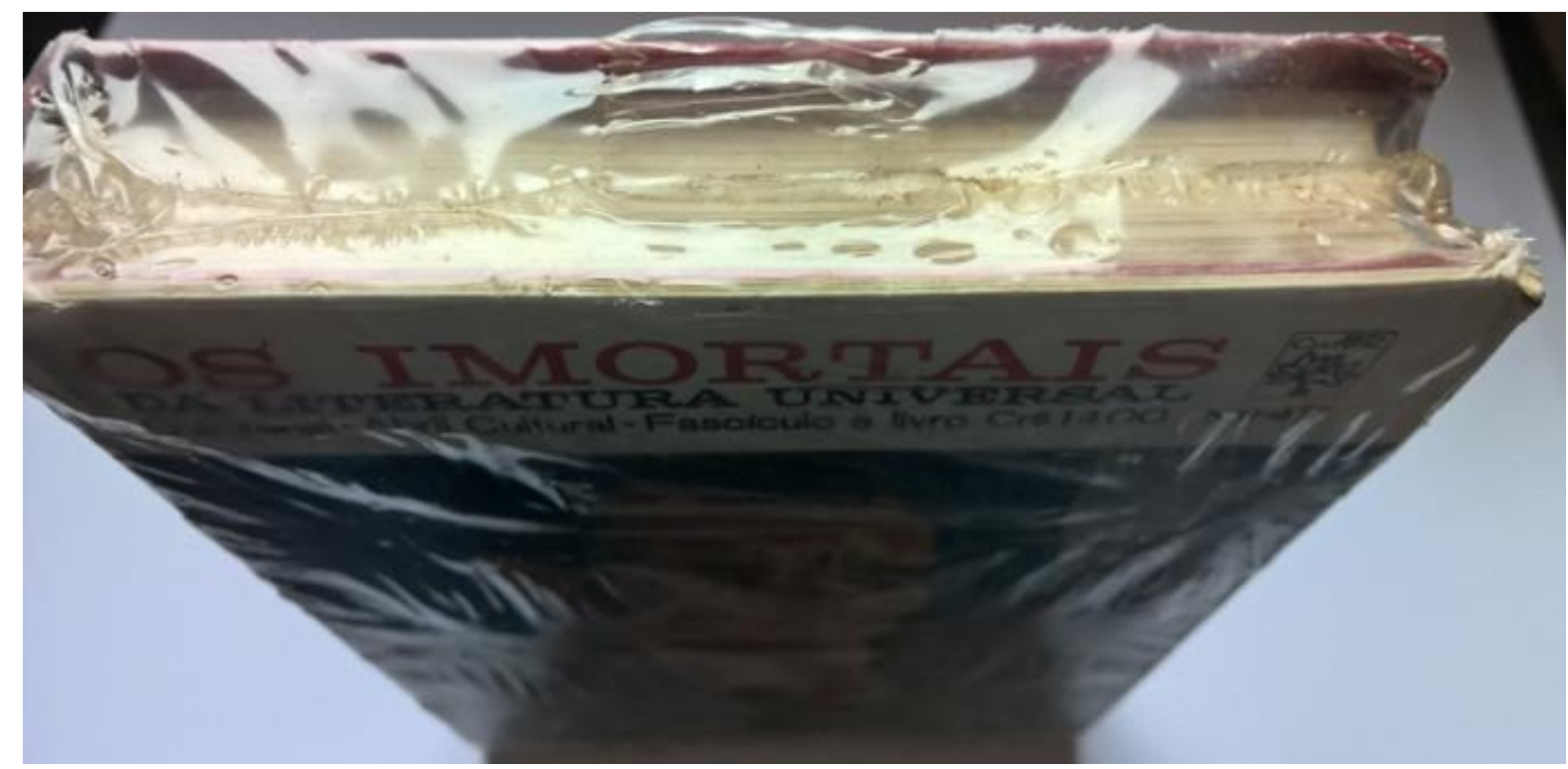

Figura 4 - Detalhe da embalagem

Fonte: Acervo pessoal.

Com relação à encadernação, pode-se observar que a coleção era composta de livros em capa dura, dotadas de ornamentos dourados (intensamente divulgados como gravados em ouro) e arabescos (Fig. 5), com o objetivo de comunicar a ideia de exemplar luxuoso, de alta qualidade e belo, para ser transmitido entre gerações da família (pautada na ideia de herança cultural a ser deixada ao espólio) e disposta na estante, para o vislumbre dos visitantes. A noção de livro como portador de cultura que transfere aos donos o caráter de erudição, por sua simples existência, esteve muito presente em toda a história do livro, ainda antes do advento da prensa de tipos móveis, e permanece válida. Basta que se observe, por exemplo, a tradição de coleções de livros estarem sempre presentes ao fundo em discursos televisionados de chefes de estado do Brasil. 
Wesley Augusto Nogueira

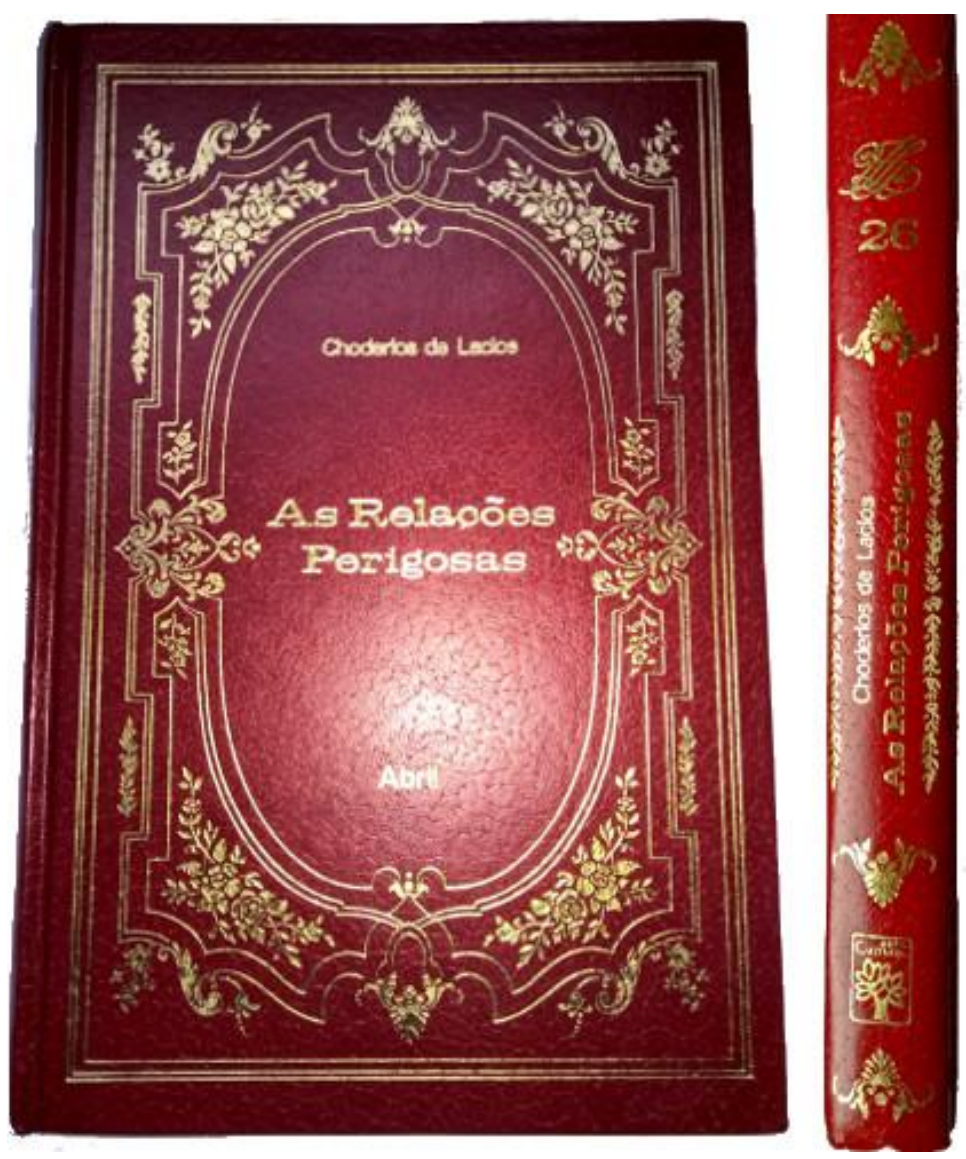

Figura 5 - Dourações e ornamentos na capa e lombada

Fonte: acervo pessoal.

Outro aspecto interessante que se apresenta em uma análise mais cuidadosa dos aspectos materiais do livro no âmbito de minha pesquisa é a análise da pasta base de celulose onde foram impressas as edições da Abril. Para reduzir custos e estabelecer uma identidade visual, os volumes de uma mesma coleção eram padronizados, com tamanho, cor, ornamentação, capa, tipo de papel utilizado, tamanho da fonte e mancha, entre outros. Entretanto, a busca pela uniformidade teve seus limites, e o próprio padrão de qualidade desenvolvido enfrentou momentos de desafio.

Um caso peculiar se revela na comparação de um livro pertencente à coleção "Os Imortais da Literatura Universal”: ao se observar o corte das páginas, nota-se de imediato que uma área das páginas do segundo exemplar estão mais escurecidas que outras (Fig. 6) e esta diferença não se apresenta em outros volumes da coleção, inclusive em outros exemplares de mesmo título. 
"O livro como uma força na História": a bibliografia como fonte de informação e método de pesquisa

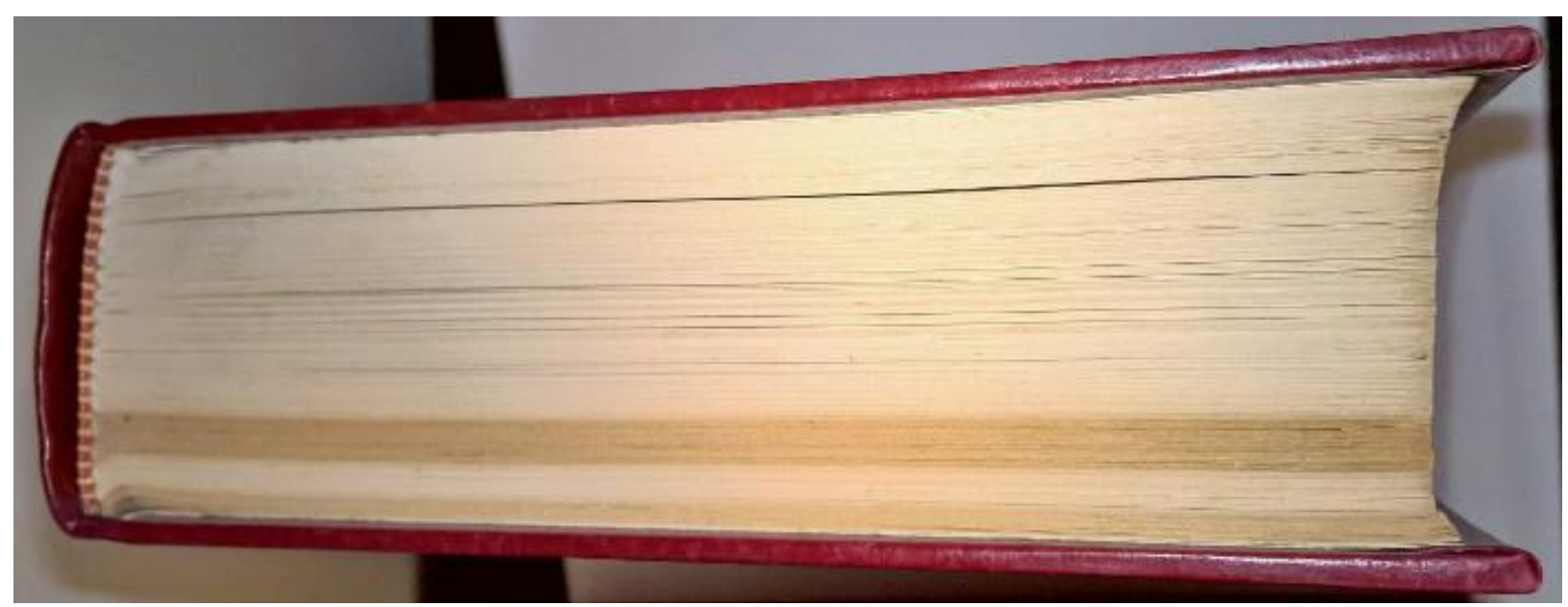

Fig. 6 - Diferença de tonalidade no corte

Fonte: Acervo pessoal.

A razão de ter ocorrido esta diferença foi revelada em uma das entrevistas realizadas: naquele período, havia vários fornecedores de papel para a editora e a preferência era pelo material de boa qualidade, conforme se nota ainda hoje pelo estado impecável dos exemplares. Porém, em determinados casos, um fornecedor poderia não conseguir atender à demanda. Restava então, aos editores, buscarem outro para substituí-lo, que, por vezes, não dispunha de papel da mesma qualidade para oferecer. A escolha estaria, assim, entre manter um padrão de qualidade ou atender ao interesse dos leitores pelo título. Fica evidente, neste caso, que a escolha foi pela publicação, em papel de menor qualidade, com diferente composição da pasta base.

Avançando mais uma etapa na análise material das coleções, temos o seguinte caso: obras com títulos idênticos, lançadas na mesma coleção e no mesmo ano, mas com capas diferentes. Qual seria o motivo? Diversificação de canais de venda. As edições em capas vermelhas, mais comuns, eram vendidas em banca no fluxo normal da publicação da coleção, em exemplares individuais com periodicidade quinzenal. As de capa marrom, por sua vez, eram sobras de estoque daquelas comercializadas em banca, que, como estratégia para minimizar perdas, eram reencadernadas e vendidas em coleção completa, com valor parcelado, pelo sistema porta-a-porta (Fig. 7). 

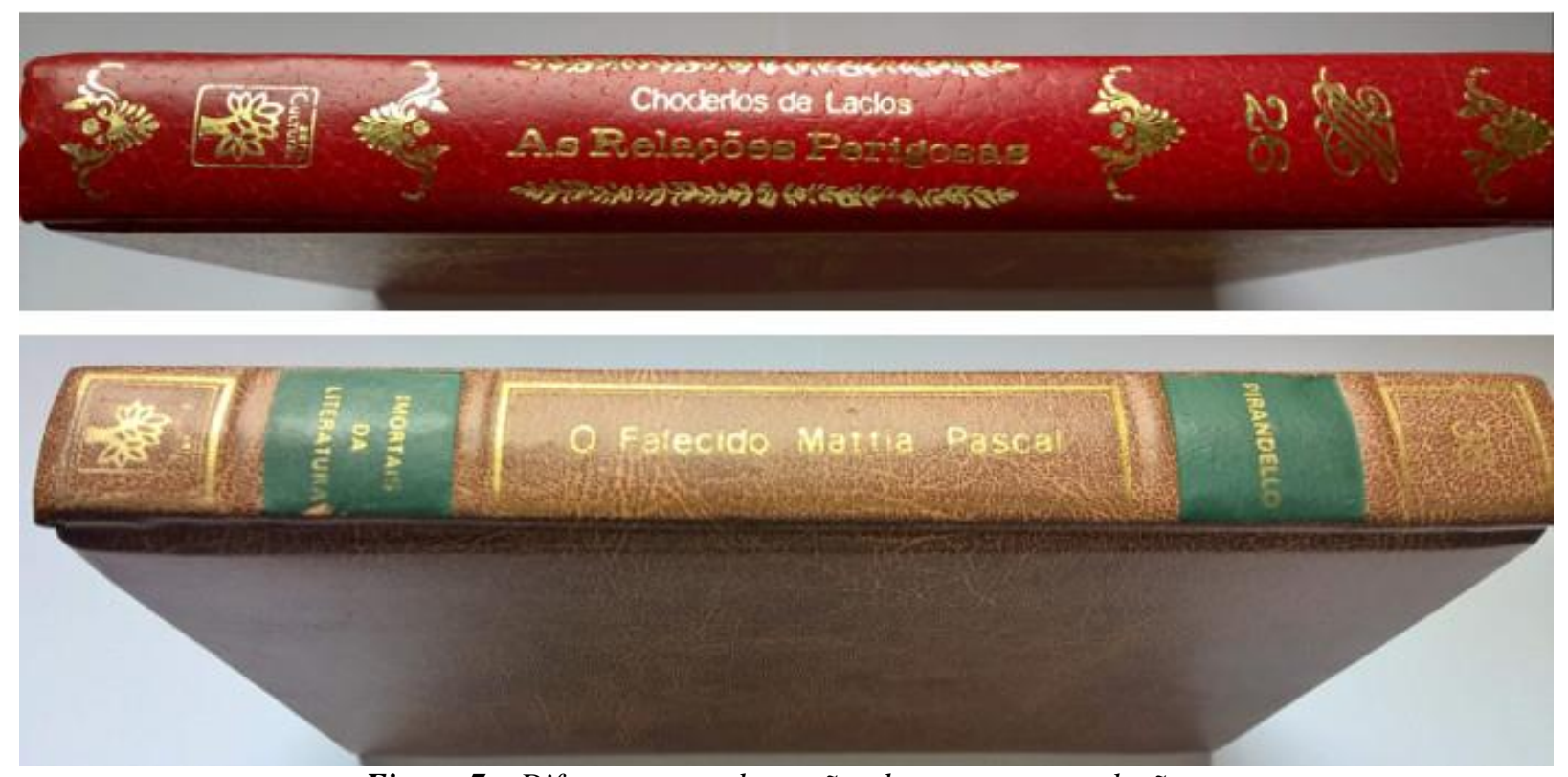

Figura 7 - Diferentes encadernações de uma mesma coleção

Fonte: Acervo pessoal.

\section{Considerações finais}

O que o catálogo das coleções nos permite compreender sobre o público consumidor e leitor das edições publicadas pela Abril Cultural durante a década de 1970? Qual o sentido da materialidade sobre o público que se desejava formar naquele período? Como a análise das folhas permite compreender condições de impressão no Brasil dos anos 1970? São questões que a análise bibliográfica forneceu pistas para a resposta.

Os exemplos que aqui se elencou são uma pequena amostra de que uma maneira diferente de se olhar um objeto pode produzir dados que seriam inatingíveis por outros métodos. Os resultados aqui alcançados, somados às informações provenientes de estudos realizados por outros métodos, tendem a ampliar o esclarecimento dobre a produção e comercialização editorial de livros populares na década de 1970. A confluência de olhares e estratégias compõe a interdisciplinaridade de que a História do Livro e a Ciência da Informação devem se valer para construir sua metodologia. É o que proclama Robert Darnton (2010, p. 149), para quem

os livros, quando tratados como objetos de estudo, também se recusam a ficar confinados dentro dos limites de uma única disciplina. Nenhuma delas - a história, a literatura, a economia, a sociologia, a bibliografia - é capaz de fazer justiça a todos os aspectos da vida de um livro. Pela sua própria natureza, portanto, a história dos livros deve operar em escala internacional e com método interdisciplinar. 
"O livro como uma força na História": a bibliografia como fonte de informação e método de pesquisa

\section{Referências}

CHARTIER, R. À beira da falésia: a história entre certezas e inquietude. Porto Alegre: UFRGS, 2002.

DARNTON, R. O beijo de Lamourette: mídia cultura e revolução. São Paulo: Companhia das Letras, 2010.

MCKENZIE, D. Bibliography and the sociology of texts. Cambridge: Cambridge University Press, 1999.

UNIVERSIDADE DE SÃO PAULO. Sistema Integrado de Bibliotecas. Departamento Técnico. Bibliotheca universitatis: livros impressos dos séculos XVII do acervo bibliográfico da Universidade de São Paulo. São Paulo: Edusp: Imprensa Oficial do Estado, 2002. 2 v. (Uspiana - Brasil 500 Anos).

WERSIG, G.; NEVELLING, U. The phenomena of interest to information science. The Information Scientist, v. 9, n. 4, p. 127-140, 1975. Disponível em:

<http://sigir.org/files/museum/pub-13/18.pdf>. Acesso em: 07 dez. 2015. 